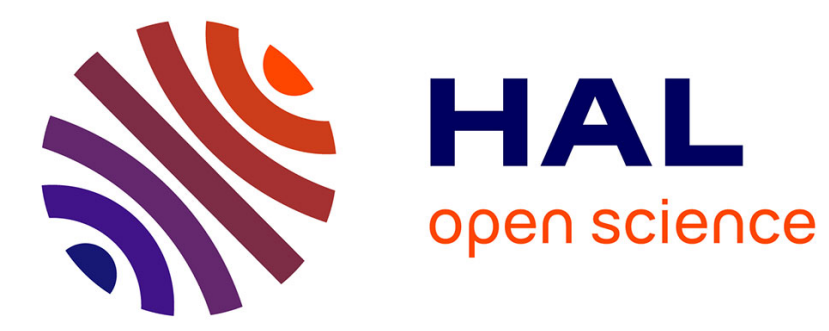

\title{
Correlations between cognitive performances and psychotic or schizotypal dimensions.
}

Andrei Szöke, Alexandre Méary, Aziz Ferchiou, Anca Trandafir, Marion Leboyer, Franck Schürhoff

\section{- To cite this version:}

Andrei Szöke, Alexandre Méary, Aziz Ferchiou, Anca Trandafir, Marion Leboyer, et al.. Correlations between cognitive performances and psychotic or schizotypal dimensions.. European Psychiatry, 2009, 24 (4), pp.244-50. 10.1016/j.eurpsy.2008.10.007 . inserm-00397381

\section{HAL Id: inserm-00397381} https://www.hal.inserm.fr/inserm-00397381

Submitted on 22 Jun 2009

HAL is a multi-disciplinary open access archive for the deposit and dissemination of scientific research documents, whether they are published or not. The documents may come from teaching and research institutions in France or abroad, or from public or private research centers.
L'archive ouverte pluridisciplinaire HAL, est destinée au dépôt et à la diffusion de documents scientifiques de niveau recherche, publiés ou non, émanant des établissements d'enseignement et de recherche français ou étrangers, des laboratoires publics ou privés. 


\section{Correlations between cognitive performances and psychotic or schizotypal dimensions}

Andrei Szöke* a,b,c , Alexandre Méary ${ }^{\mathrm{a}, \mathrm{b}, \mathrm{c}}$, Aziz Ferchiou ${ }^{\mathrm{a}, \mathrm{b}, \mathrm{c}}$, Anca Trandafir ${ }^{\mathrm{c}}$, Marion Leboyer $^{\mathrm{a}, \mathrm{b}, \mathrm{c}}$, Franck Schürhoff ${ }^{\mathrm{a}, \mathrm{b}, \mathrm{c}}$

a INSERM U955, 94000, Créteil, France;

${ }^{\mathrm{b}}$ Université Paris 12, Faculté de Médecine, IFR 10, 94000, Créteil, France

c AP-HP, Groupe “Chenevier-Mondor", Pôle de Psychiatrie, 94000, Créteil, France.

\section{Abstract}

Objective To test if specific correlations exist between cognitive measures and psychotic dimensions in schizophrenic subjects and if similar correlations, between cognition and schizotypal dimensions, are present in non-psychotic subjects.

Methods We administered the same battery of cognitive tests (Source Monitoring, Verbal Fluency [VF] and Stroop tests) to schizophrenic subjects $(\mathrm{N}=54)$, their first-degree relatives $(\mathrm{N}=37)$ and controls $(\mathrm{N}=41)$. Scores of negative, positive and disorganisation dimensions were derived from the Signs and Symptoms of Psychotic Illness scale in schizophrenic subjects, and from the Schizotypal Personality Questionnaire in relatives and controls.

Results In schizophrenic subjects, as hypothesized, the negative dimension correlated with performance on VF and disorganisation with performance in the Stroop test. The positive dimension did not correlate with any cognitive measure.

With only one exception, the significant correlations observed in non-psychotic subjects did not match correlations seen in schizophrenic subjects. In non-psychotic subjects greater disorganisation was associated with more clustered words in VF suggesting that excessive automatic spreading of activation in semantic networks could underlie this dimension.

Conclusion As a whole, data lent partial support to our hypothesis of specific cognitiveclinical correlations in schizophrenic subjects but did not support the existence of similar correlations in non-psychotic subjects. 
Key words: Schizophrenia, schizotypal, disorganisation, cognition, verbal fluency

* Corresponding Author: Andrei Szöke, andrei.szoke@ach.aphp.fr

Pôle de Psychiatrie, Hôpital "A. Chenevier", 40, rue de Mesly, 94000, Créteil, France

Telephone : $+33(0) 149813051$,

Fax : + $33(0) 149813059$ 


\section{Introduction}

Important advances have been made in identifying the risk factors and in identifying, describing, and classifying the clinical symptoms of schizophrenia. However, the link between specific risk factors and particular clinical aspects is less well understood. Cognitive deficits may occupy an intermediate position between risk/vulnerability factors and clinical manifestations [18]. Thus, studying their correlation with identified risk factors and/or with the clinical dimensions may help to bridge the gap.

A tri-dimensional model for psychotic symptomatology emerged as an empirical finding [26] and has since been repeatedly validated [16]. Based on theoretical considerations and empirical findings, specific cognitive deficits have been suggested as explanations for each of the three psychotic dimensions. For example, Frith [13] hypothesized that the negative dimension is the result of a deficit of willed action, resulting in difficulties in self-initiation and maintenance of action. For the disorganization dimension the proposed deficit consists in difficulties in suppressing inappropriate mental activity [3] which leads to distractibility and poor inhibition of automatic (inadequate) responses [35]. Finally, the positive dimension has been linked to deficits in self-monitoring [13] and, as a consequence, to difficulties in recognising his/her own thoughts and actions.

Studies exploring the correlation between psychotic dimensions and cognitive performances in schizophrenic subjects provided partial support to these hypotheses. Although the negative dimension correlates with most cognitive deficits $[33,18]$, impairments on tests that depend on initiation and maintenance of action, such as verbal fluency (VF), were more constantly associated with high scores of negative signs [14, 20]. By contrast, most studies using classical neuro-psychological tests did not find associations with the positive dimension [7, 15]. However, several studies found an association between the positive dimension (or 
individual positive symptoms) and source monitoring (SM) deficits $[5,6,12]$ which are explained, at least in part, by difficulties in self-monitoring. Disorganisation was associated with deficits in attention tasks, particularly tasks necessitating sustained attention in the presence of distracters, such as the Stroop Word and Colour test (SWCT) [3, 24]. A recent meta-analysis [8] of studies reporting correlations between the three psychotic dimensions and commonly used tests of executive function reached similar conclusions. This analysis found that the negative and disorganisation dimensions, but not positive dimension, were significantly associated with impairment on executive tests. Furthermore, in this study VF and SWCT showed some specificity in their correlations to the psychotic dimensions as VF was three times more strongly associated with negative symptoms than with disorganisation, and the SWCT showed a twofold difference in the opposite direction.

Although each of the specific associations mentioned before has been reproduced, there are also several divergent findings in the literature. A possible explanation for the heterogeneity of results is the presence of confounding factors. Among these, medication and the clinical state of the subjects (chronic, acute, in remission etc.) are probably the most important.

To avoid these confounding factors, some authors have studied the correlation between schizotypal traits and cognitive performances in schizotypal subjects [34], in subjects at risk for schizophrenia [38], and in normal controls [9]. Schizotypal traits may be grouped along the same three dimensions as psychotic symptoms (positive, negative and disorganisation), are stable, may be reliably assessed, and are present in subjects that are usually not taking psychotropic medication.

Studies exploring the correlation between the three schizotypy dimensions and neurocognitive deficits are surprisingly rare $[22,34,38]$ and provide results for only a few neurocognitive measures. Thus, it is unclear if these correlations parallel those seen in schizophrenic subjects. 
Most of the studies that investigated correlations between psychotic or schizotypal dimensions and cognitive performance were exploratory in design and used large cognitive batteries. This led to multiple statistical tests and, for this reason, increased the chance of spurious, false positive, findings.

There are currently no data from studies investigating clinical-cognitive correlation, in both schizophrenic and non-psychotic subjects, using the same cognitive battery.

In this study, we tested two hypotheses: 1/ that correlations exist between specific cognitive performances and specific psychotic or schizotypal dimensions and $2 /$ that correlations in non-psychotic subjects parallel those seen in schizophrenic subjects. To test these hypotheses, we assessed the correlations between cognitive performances and clinical dimensions in schizophrenic subjects and in non-psychotic subjects (first degree relatives of schizophrenic subjects and normal controls).

\section{Methods}

\subsection{Subjects}

Patients meeting DSM-IV [1] criteria for schizophrenia or schizoaffective disorder were consecutively recruited. Patients were interviewed by an experienced psychiatrist using the French version of the Diagnostic Interview for Genetic Studies (DIGS) [30, 31] to confirm their diagnosis. Most of the schizophrenic subjects were inpatients at the time of the study. They were approached for inclusion when their treating psychiatrist considered them able to undergone the study procedures.

First-degree relatives were interviewed with the DIGS to exclude those presenting psychotic disorders.

Healthy controls were blood donors at the "Etablissement Français du Sang" in Créteil. Controls were included after being interviewed with the DIGS and the FIGS (Family 
Interview for Genetic Studies) [27] to confirm the absence of personal or family history of DSM IV axis I or II disorders.

For inclusion in the study, all subjects were required to be normothymic, as evaluated by the Montgomery and Asberg Depression Rating Scale [28] and the Bech and Rafaelsen mania rating scale [4]. Subjects were included only if aged between 18 and 60 years, and if they had no history of neurological disease or current substance abuse.

The research ethics board of Salpêtrière Hospital reviewed and approved the study. The study was described in detail to the subjects, who then gave written informed consent for participation.

\subsection{Clinical assessment}

The symptoms in schizophrenic subjects were assessed using the Signs and Symptoms of Psychotic Illness (SSPI) scale [19, 25]. As noted by Grube et al. [16], some symptoms tend to be associated with different dimensions across various studies because their polyfactorial nature and/or differences in subject characteristics across studies. Using symptoms that are inconsistently associated with one dimension for calculating the score for that dimension may lessen its validity. Thus, in this study we used only the core symptoms of each dimension, i.e. signs and symptoms that loaded similarly in the two validation studies (see table 1) [19, 25]. The three schizotypy dimensions were derived in healthy subjects (controls and relatives) based on the answers to the Schizotypal Personality Questionnaire - SPQ [11, 32]. As for the SSPI, we calculated the three schizotypal dimensions using only the traits that loaded on similar dimensions in the two validation studies (table 1)

\section{Insert Table 1.}




\subsection{Cognitive assessment}

We tested our hypotheses using a battery of three tests: a Source Monitoring Test (SMT), the SWCT and a test of Semantic (category) VF.

The SMT was specifically designed for this study. We defined four semantic categories that are finite and are everyday knowledge: temperate climate fruits, Olympic sports, European countries and numbers from 50 to 70 . Each possible example from these categories was printed on a unique card. At the first stage of the test, twelve items were selected from each category. Two were generated by the subjects after the category was announced, two were read aloud by the subject, two more were read silently by the subject, two were read aloud by the examiner and four were added from the remaining cards ("new" items). The recognition stage took place after the subject underwent the two other tests (SWCT and VF). Only at this stage was the subject informed that the aim of the test was to remember the source of the items with which he/she was presented. The 48 selected cards were presented to the subject in random order and he/she had to decide if this was his/her example, one of the examples he/she read silently or aloud, an example read by the examiner or a new item. The variables derived from this test were: total number of correct responses $(\mathrm{CR})$, number of false alarms (FA = new items that were falsely designated as previously presented), self-discrimination index $(\mathrm{SDI}=$ number of times the subject correctly identified himself as the source of the item) and external bias $(\mathrm{EB}=$ number of items erroneously attributed to the examiner).

For the VF, the subjects were instructed to provide as many names of animals as possible in a 2-minute period. The production of items in VF tasks results from two processes [36]: clustering, i.e. production of related items (e.g. sheep, cow, goat, pig - farm animals) and switching between those clusters (e.g. switching from farm animals to pets). We used the total number of items produced (excluding errors), the number of switches (Swi) and number of clustered items (Clust) calculated according to the procedures described by Troyer et al. [36]. 
The SWCT consisted of three trials of 45 seconds each, in which the subject successively read aloud the names of colours printed in black, names the colour with which strings of "X"s are printed and finally names the colour with which the name of a different colour is printed (e.g. red printed in blue - correct answer blue). Two variables were generated using the number of items from each trial: the number of items in the last trial (IntTot) and an interference index (IntIdx), reflecting the extra time needed per item in the last trial compared with the second trial.

\subsection{Statistical analysis}

We compared demographic characteristics (age, sex distribution, education level) of the three groups using an ANOVA (for continuous variables) and the Chi2 test (for categorical variables).

We compared the cognitive performances of the three groups using the SAS mixed procedure. This procedure, based on a general linear mixed model, enabled us to adjust comparisons for demographic characteristics and also for non-independence of observations in subjects from the same family.

Our main analysis (testing our hypotheses of specific and similar clinical-cognitive correlation) involved two steps. In the first step, we selected the clinical dimensions that had a statistically significant influence on the cognitive measures using a stepwise backward regression. This is a classical automatic procedure for selecting the best subset of predictor variables - for a detailed presentation see [2]. For this step of the procedure all demographic and clinical variables were entered as potential explanatory variables. Only the significant variables, at a threshold of 0.1 , were kept in the final model. The stepwise backward regression was applied in schizophrenic and in non-psychotic (relatives and controls) groups separately. For the non-psychotic group, "family" was entered as a random effect variable. 
Analyzing the two non-psychotic groups together limited the number of statistical tests (and thus the risk of false positive findings) and augmented the sample size (thus the statistical power). We used this procedure, as we did not expected different correlations within the two non-psychotic groups.

Then, we calculated partial correlations between clinical and cognitive variables for all the significant associations identified in step I. If needed, the correlation sign was changed so that negative correlations always reflected poorer cognitive performance in more symptomatic subjects.

When significant correlations were observed in the combined group, we also calculated the correlations in each non-psychotic group.

All statistical analyses were generated using SAS software, Version 9 of the SAS System for Windows (Copyright (C) 2002-2003 by SAS Institute Inc., Cary, NC, USA).

\section{Results}

A total of 133 subjects (54 schizophrenic subjects, 37 of their first degree relatives and 42 controls) were included in this study. Their demographic and clinical characteristics are summarized in Table 2. There were significant differences between groups for all demographic variables, mainly due to the schizophrenic group being younger, less educated and with a larger proportion of male subjects.

\section{Insert Table 2}

The results of cognitive testing in the three groups are presented in Table 3.

\section{Insert Table 3}

In schizophrenic subjects, 4 cognitive variables (CR from the SMT, the two variables from the SWCT and Swi from the VF) showed significant association with clinical dimensions. 
Partial correlations showed that for all these variables better results were associated with less negative symptoms. The total number of items in the last trial (interference condition) of the SWCT was also negatively correlated with the disorganisation dimension.

Only three cognitive variables were significantly related to clinical dimensions in nonpsychotic subjects and all these variables were derived from the VF test. The total number of items and Clust were both positively correlated with the disorganisation dimension (i.e. subjects with greater disorganisation scores had better results). In contrast, Swi was negatively correlated with the negative dimension.

All significant clinical-cognitive correlations are presented in Table 4.

When correlations were calculated separately in controls and relatives the results (not shown) remained essentially the same. Correlations were in the same direction as those in the pooled samples, and their values were similar to those in the combined group (between 0.26 and $0.46)$.

Because some authors calculated the raw (un-partialled) correlations between the cognitive variables and clinical dimensions we also calculated them to allow comparisons. Using this procedure we obtained similar results.

In non-psychotic subjects the same three correlations (involving variables from the VF) reached statistical significance (all three correlations greater than .25 ). All other correlations were less than .25 and did not approach significance $(\mathrm{P}>.1)$.

In schizophrenic subjects only correlations between the negative dimension and the variables from the Stroop test and number of switches in the VF test remained greater than .25 and reached statistical significance. All other correlations were less than .25 and did not approach significance $(\mathrm{P}>.1)$. (Detailed results available on request)

\section{Insert Table 4}




\section{Discussion}

Our first hypothesis was that specific correlations exist between cognitive variables and clinical dimensions. In schizophrenic patients, our results lend partial support to this hypothesis as significant negative correlations were observed between the total number of items in the SCWT and disorganisation, and also between one of the variables reflecting VF performance (Swi) and the negative dimension.

However, no significant correlation was found between the positive dimension and performance with the SMT. Our results contrast those from several other studies that found significant correlation between the SMT deficits and the positive dimension [6] or individual positive symptoms $[5,21]$. However there are also reports of results similar to those obtained in the present study. Vinogradov et al. [37] found that SMT errors were not associated with positive symptoms and were only weakly related to negative symptoms. Important differences in the characteristics of the SMT used (e.g. time between generation and recognition phases, difficulty of the task, etc.) and the clinical state of subjects included (chronic or acute, stable or not etc.) make comparison between studies difficult [10]. However, most previous studies did not investigate correlations with the negative dimension. Furthermore, with the exception of the Vinogradov et al. study [36], most studies investigating the negative dimension were based on a dichotomous (positive-negative) model for schizophrenic symptomatology, thus differing from the trichotomous model used in this study.

In contrast to our hypothesis of particular clinical-cognitive correlation, the negative dimension appears to be linked to a more general cognitive impairment showing negative correlations with performances in all three tests. This last finding (the fact that general cognitive deficit was associated with the negative dimension) is consistent with results from several previous studies [17]. 
One possible explanation for this pattern of results (significant correlations with the negative dimension that contrast with the paucity or absence of correlations with the positive and disorganised dimensions) is that the negative dimension is more stable than the other two. For clinical dimensions that show marked temporal variation, the SSPI (which is scored based on the previous week's symptoms) reflects neither the clinical state at the time of testing nor a more general, trait-like characteristic that could, for example, be derived from life-time assessments. The choice of the time frame is clearly of little importance in the case of more stable clinical dimensions (like the negative dimension).

Various populations of subjects (for example patients with chronic and stable positive and disorganised symptoms) should be studied to overcome this potential limitation. Another option, which was used in this study, is to study healthy subjects in which schizotypal traits (i.e. stable measures) are used for the clinical assessment.

Results in the group of non-psychotic subjects were not consistent with our initial hypothesis. In particular, no correlation was found between measurements from the SMT and SCWT and the clinical dimensions.

To our knowledge this is the first study to explore, in non-psychotic subjects, the correlation between schizotypal dimensions and a source monitoring performances. A possible explanation for our negative findings is the low mean scores and limited variation in the schizotypal dimensions in our sample. Further studies, in populations showing greater variations in scores of schizotypal dimensions, in particular of positive dimension (e.g. subjects with schizotypal personality disorder), are needed to further explore the presence of such correlations.

In the sample of non-psychotic subjects, the correlation between the number of switches in the VF test and the negative dimension of schizotypy was the only result consistent with our initial hypothesis. 
An unexpected finding was the positive correlation between disorganisation and both the Clust and the number of total items in VF, i.e. better performances in subjects with greater disorganisation scores. In our study, the "disorganisation dimension" in the SPQ equated to the "odd speech" trait, which is mainly derived from items that are used to assess poor speech organisation. Several previous studies have suggested that speech or thought disorder (TD) in schizophrenic [15] or normal subjects [29] result from an excessive automatic spreading of activation in semantic networks. Our results suggest a similar hypothesis, in which excessive automatic (thus rapid) associations promote large clusters and a greater number of items in the VF but at the same time lessen the logical organisation of speech. Furthermore, functional neuroimaging studies suggest that specific abnormalities are present in the temporal regions of schizophrenic patients with TD [23]; the temporal region is also the region implicated in the clustering (but not in the switching) process of VF. This also suggests that thought/speech abnormalities and the clustering process are linked.

We also hypothesised that similar correlations exist in the two populations studied.

Only one correlation, between the negative dimension and the number of switches in VF was similar in the two populations. This correlation was consistent with our initial hypotheses. However, as discussed previously, in the sample of schizophrenic subjects, the negative dimension was associated with poor results in all tests, leading to significant, negative correlations with almost half of the cognitive measures used in this study. Thus, unless these findings are reproduced in future studies, the possibility that in our study similar correlations were observed by chance cannot be excluded.

The disorganisation dimension showed different correlations in the two samples. Several differences in the clinical measures used in the two groups may explain these differences. One difference already mentioned is that the SSPI explores the clinical state, whereas the SPQ explores stable traits. Another difference is that the SSPI is based on clinician's assessment 
although the SPQ is based on self-report. Probably, a more important difference is that impaired attention, an item that usually enters into the composition of disorganisation, is not explored by the SPQ. This may explain why the SCWT measurements did not correlate with the SPQ dimension of disorganisation.

Thus, to explore whether similar correlations exist with schizotypal traits and with psychotic symptoms, greater effort must be devoted to developing parallel assessments (i.e. containing similar items) for schizophrenic and schizotypal symptoms.

\section{Conclusion}

Our study lent partial support to our initial hypothesis of specific correlations between schizophrenic dimensions and cognitive performances but did not support the existence of similar correlations in schizophrenic and non-psychotic subjects. Before our initial hypotheses can be rejected (or validated), several limitations of the present study must be addressed in further research.

The association between Clust and measures of poorer speech organisation in non-psychotic subjects was not initially hypothesised. Thus, although this result is in line with prior findings linking thought disorder and excessive automatic spreading of activation in semantic networks, it needs also to be validated in further studies.

\section{Acknowledgements}

This research was supported by grants from INSERM and "Délégation à la Recherche Clinique de l'AP-HP" (PHRC AOM 98152). A.S. and A.M. received grants from the "Fondation pour la Recherche Médicale".

We thank M.J. Pereira-Gomes and E. Abadie for technical assistance. 


\section{References}

[1] American Psychiatric Association. Diagnostic and Statistical Manual of Mental Disorders, Fourth Edition. Washington, DC: American Psychiatric Association; 1994.

[2] Armitage, P., Berry, G., Matthews J.N.S. Statistical methods in medical research, $4^{\text {th }}$ ed. Blackwell Science, Oxford; 2002.

[3] Baxter RD, Liddle PF. Neuropsychological deficits associated with schizophrenic syndromes. Schizophr Res 1998; 30(3):239-49.

[4] Bech P, Bolwig TG, Kramp P, Rafaelsen OJ. The Bech-Rafaelsen Mania Scale and the Hamilton Depression Scale. Acta Psychiatr Scand 1979;59(4):420-30.

[5] Brébion G, Amador X, David A, Malaspina D, Sharif Z, Gorman JM. Positive symptomatology and source monitoring failure in schizophrenia: an analysis of symptom-specific effects. Psychiatry Res 2000;95(2):119-31.

[6] Brébion G, Gorman JM, Amador X, Malaspina D, Sharif Z. Source monitoring in schizophrenia: characterisation and associations with positive and negative symptomatology. Psychiatry Res 2002;112(1):27-39.

[7] Brekke JS, Raine A, Thomson C. Cognitive and psychophysiological correlates of positive, negative, and disorganized symptoms in the schizophrenia spectrum. Psychiatry Res. 1995; 57(3):241-50.

[8] Dibben CR, Rice C, Laws K, McKenna PJ. Is executive impairment associated with schizophrenic syndromes? A meta-analysis. Psychol Med. 2008; 30:1-12. [Epub ahead of print]

[9] Dinn WM, Harris CL, Aycicegi A, Greene P, Andover MS. Positive and negative schizotypy in a student sample: neurocognitive and clinical correlates. Schizophr Res 2002;56(1-2):171-85. 
[10] Ditman T, Kuperberg GR. A source-monitoring account of auditory verbal hallucinations in patients with schizophrenia. Harv Rev Psychiatry 2005;13(5):280-99.

[11] Dumas P, Bouafia S, Gutknecht C, Saoud M, Dalery J, d'Amato T. Validation de la version française du questionnaire de personnalité schizotypique de Raine - approche catégorielle et dimensionnelle des traits de personnalité schizotypique dans une population d'étudiants. Encéphale 2000;26(5):315-22.

[12] Franck N, Rouby P, Daprati E, Dalery J, Marie-Cardine M, Georgieff N. Confusion between silent and overt reading in schizophrenia. Schizophrenia Res 2000;41(2):35764.

[13] Frith CD. The cognitive neuropsychology of schizophrenia. Lawrence Erlbaum. Hove.

[14] Good KP, Rabinowitz J, Whitehorn D, Harvey PD, DeSmedt G, Kopala LC. The relationship of neuropsychological test performance with the PANSS in antipsychotic naïve, first-episode psychosis patients. Schizophr Res 2004;68(1):11-9.

[15] Gouzoulis-Mayfrank E, Voss T, Mörth D, Thelen B, Spitzer M, Meincke U. Semantic hyperpriming in thought-disordered patients with schizophrenia: state or trait?--a longitudinal investigation. Schizophr Res 2003;65(2-3):65-73.

[16] Grube BS, Bilder RM, Goldman RS. Meta-analysis of symptom factors in schizophrenia. Schizophr Res 1998;31(2-3):113-20.

[17] Harvey PD, Koren D, Reichenberg A, Bowie CR. Negative symptoms and cognitive deficits: what is the nature of their relationship? Schizophr Bull 2006;32(2):250-8.

[18] Heydebrand G, Weiser M, Rabinowitz J, Hoff AL, DeLisi LE, Csernansky JG. Correlates of cognitive deficits in first episode schizophrenia. Schizophr Res 2004;68(1):1-9. 
[19] Houenou J, Szöke A, Méary A, Loze J-Y, Mathieu F, Leboyer M, et al. Psychometric properties of the French version of the Signs and Symptoms of Psychotic Illness (SSPI) scale. Encéphale 2007;33(5):744-50.

[20] Howanitz E, Cicalese C, Harvey PD. Verbal fluency and psychiatric symptoms in geriatric schizophrenia. Schizophr Res 2000;42(3):167-9.

[21] Keefe RSE, Arnold MC, Bayen UJ, McEvoy JP, Wilson WH. Source monitoring deficits for self-generated stimuli in schizophrenia: multinomial modelling of data from three sources. Schizophr Res 2002;57(1):51-67.

[22] Kerns JG. Schizotypy facets, cognitive control, and emotion. J Abnorm Psychol 2006;115(3):418-27.

[23] Kircher TT, Liddle PF, Brammer MJ, Williams SC, Murray RM, McGuire PK. Reversed lateralization of temporal activation during speech production in thought disordered patients with schizophrenia. Psychol Med 2002;32(3):439-49.

[24] Liddle PF, Morris DL. Schizophrenic syndromes and frontal lobe performance. Br J Psychiatry 1991;158(3):340-5.

[25] Liddle PF, Ngan ETC, Duffield G, Kho K, Warren AJ. Signs and Symptoms of Psychotic Illness (SSPI): a rating scale. Br J Psychiatry 2002;180(1):45-50.

[26] Liddle PF. Schizophrenic syndromes, cognitive performance and neurological dysfunction. Psychol Med 1987;17(1):49-57.

[27] Maxwell ME. Family Interview for genetic Studies. Clinical Neurogenetic Branch, Intramural Research Program, NIMH;1992.

[28] Montgomery SA, Asberg M. A new depression scale designed to be sensitive to change. Br J Psychiatry 1979;134(4):382-9. 
[29] Moritz S, Andresen B, Domin F, Martin T, Probsthein E, Kretschmer G, et al. Increased automatic spreading activation in healthy subjects with elevated scores in a scale assessing schizophrenic language disturbances. Psychol Med 1999;29(1):161-70.

[30] Nurnberger JIJr, Blehar MC, Kaufmann CA, York-Cooler C, Simpson SG, HarkavyFriedman J, et al. Diagnostic interview of genetic studies. Rationale, unique features and training. NIMH Genetics Initiative. Arch Gen Psychiatry 1994;51(11):849-59.

[31] Preisig M, Fenton BT, Matthey ML, Berney A, Ferrero F. Diagnostic interview for genetic studies (DIGS): inter-rater and test-retest reliability of the French version. Eur Arch Psychiatry Clin Neurosci 1999;249(4):174-9.

[32] Raine A. The SPQ: a scale for the assessment of schizotypal personality based on DSM III R criteria. Schizophr Bull 1991;17(4):555-64.

[33] Rocca P, Castagna F, Marchiaro L, Rasetti R, Rivoira E, Bogetto F. Neuropsychological correlates of reality distortion in schizophrenic patients. Psychiatry Res.;145:49-60.

[34] Suhr JA, Spitznagel MB. Factor versus cluster models of schizotypal traits. II: relation to neuropsychological impairment. Schizophr Res 2001; 52(3):241-50.

[35] Torres IJ, O'Leary DS, Andreasen NC. Symptoms and interference from memory in schizophrenia: evaluation of Frith's model of willed action. Schizophr Res. 2004; 69:3543.

[36] Troyer AK, Moscovitch M, Winocur G. Clustering and switching as two components of verbal fluency: evidence from younger and older healthy adults. Neuropsychology 1997;11(1):138-46.

[37] Vinogradov S, Willis-Shore J, Poole JH, Marten E, Ober BA, Shenaut GK. Clinical and neurocognitve aspects of source monitoring errors in schizophrenia. Am J Psychiatry 1997;154(11):1530-7. 
[38] Vollema MG, Postma B. Neurocognitive correlates of schizotypy in first degree relatives of schizophrenia patients. Schizophr Bull 2002;28(3):367-77. 
Table 1. The structure of the clinical dimensions used in our study

\begin{tabular}{|c|c|c|}
\hline & SSPI & SPQ \\
\hline \multirow{3}{*}{ Positive } & Hallucinations & Unusual perceptual experiences \\
\hline & Delusions & Magical thinking \\
\hline & & Ideas of reference \\
\hline \multirow{3}{*}{ Negative } & Flat affect & Constricted affect \\
\hline & Poverty of speech & Social anxiety \\
\hline & Underactivity & No close friends \\
\hline \multirow{2}{*}{ Disorganisation } & Thought form disorder & Odd speech \\
\hline & Impaired attention & \\
\hline \multirow{2}{*}{$\begin{array}{l}\text { Excluded items (items } \\
\text { that load on different }\end{array}$} & Peculiar behaviour (Exc/ Dis) $^{a}$ & Odd behaviour (Dis/ Pos) $^{\mathrm{a}}$ \\
\hline & 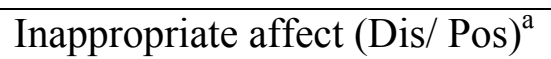 & Paranoid ideation (Pos \& Neg/ Pos) ${ }^{a}$ \\
\hline dimensions in the & Anhedonia $(\mathrm{Neg} / \mathrm{Dep})^{\mathrm{a}}$ & \\
\hline validation studies) & & \\
\hline
\end{tabular}

${ }^{a}$ Dimension(s) on which the item loaded in the English version/ Dimension(s) on which the item loaded in the French version $(\mathrm{Pos}=$ Positive Dimension, Neg = Negative Dimension, Dis $=$ Disorganisation, Exc $=$ Psychomotor Excitation, Dep $=$ Depressive Dimension $)$ 
Table 2 Clinical and demographical variables in the three groups of subjects

\begin{tabular}{|c|c|c|c|c|}
\hline & & $\begin{array}{c}\text { Schizophrenic } \\
\text { subjects }\end{array}$ & Relatives & Normal Controls \\
\hline \multicolumn{2}{|l|}{$\mathrm{N}$} & 54 & 37 & 42 \\
\hline \multicolumn{2}{|c|}{ Age $[\text { Mean }(\mathrm{SD})]^{\mathrm{a}}$} & $33.83(9.53)$ & $45.68(12.57)$ & $41.5(13.46)$ \\
\hline \multicolumn{2}{|c|}{$\operatorname{Sex} M[N(\%)]^{b}$} & $39(72.22)$ & $18(48.65)$ & $22(52.38)$ \\
\hline \multicolumn{2}{|c|}{${\text { High School }[N(\%)]^{c}}^{c}$} & $20(37.04)$ & $29(78.38)$ & $35(83.33)$ \\
\hline Clinical & Positive & $2.57(2.47)$ & $1.49(1.87)$ & $1.90(2.18)$ \\
\hline dimensions & & {$\left[\operatorname{Max}^{\mathrm{d}}=8\right]$} & {$\left[\operatorname{Max}^{\mathrm{d}}=25\right]$} & {$\left[\operatorname{Max}^{\mathrm{d}}=25\right]$} \\
\hline \multirow[t]{4}{*}[\text{Mean}(\mathrm{SD})]{} & Negative & $3.16(3.08)$ & $4.03(4.00)$ & $4.31(3.65)$ \\
\hline & & {$\left[\operatorname{Max}^{\mathrm{d}}=12\right]$} & {$\left[\operatorname{Max}^{\mathrm{d}}=25\right]$} & {$\left[\operatorname{Max}^{\mathrm{d}}=25\right]$} \\
\hline & Disorganisation & $1.56(1.59)$ & $1.46(1.79)$ & $1.95(2.17)$ \\
\hline & & {$\left[\operatorname{Max}^{\mathrm{d}}=8\right]$} & {$\left[\operatorname{Max}^{\mathrm{d}}=9\right]$} & {$\left[\operatorname{Max}^{\mathrm{d}}=9\right]$} \\
\hline
\end{tabular}

${ }^{\mathrm{a}}$ significant differences $[F(2)=12.01, P<0.0001]$

${ }^{\mathrm{b}}$ significant differences[Chi2 $\left.(2)=6.31, P=0.004\right]$

${ }^{\mathrm{c}}$ significant differences [Chi2 $\left.(2)=26.86, P<0.0001\right]$

${ }^{\mathrm{d}} \mathrm{Max}=$ total number of items for the dimension $=$ maximum score; 
Table 3 Results of the cognitive assessment in the three groups

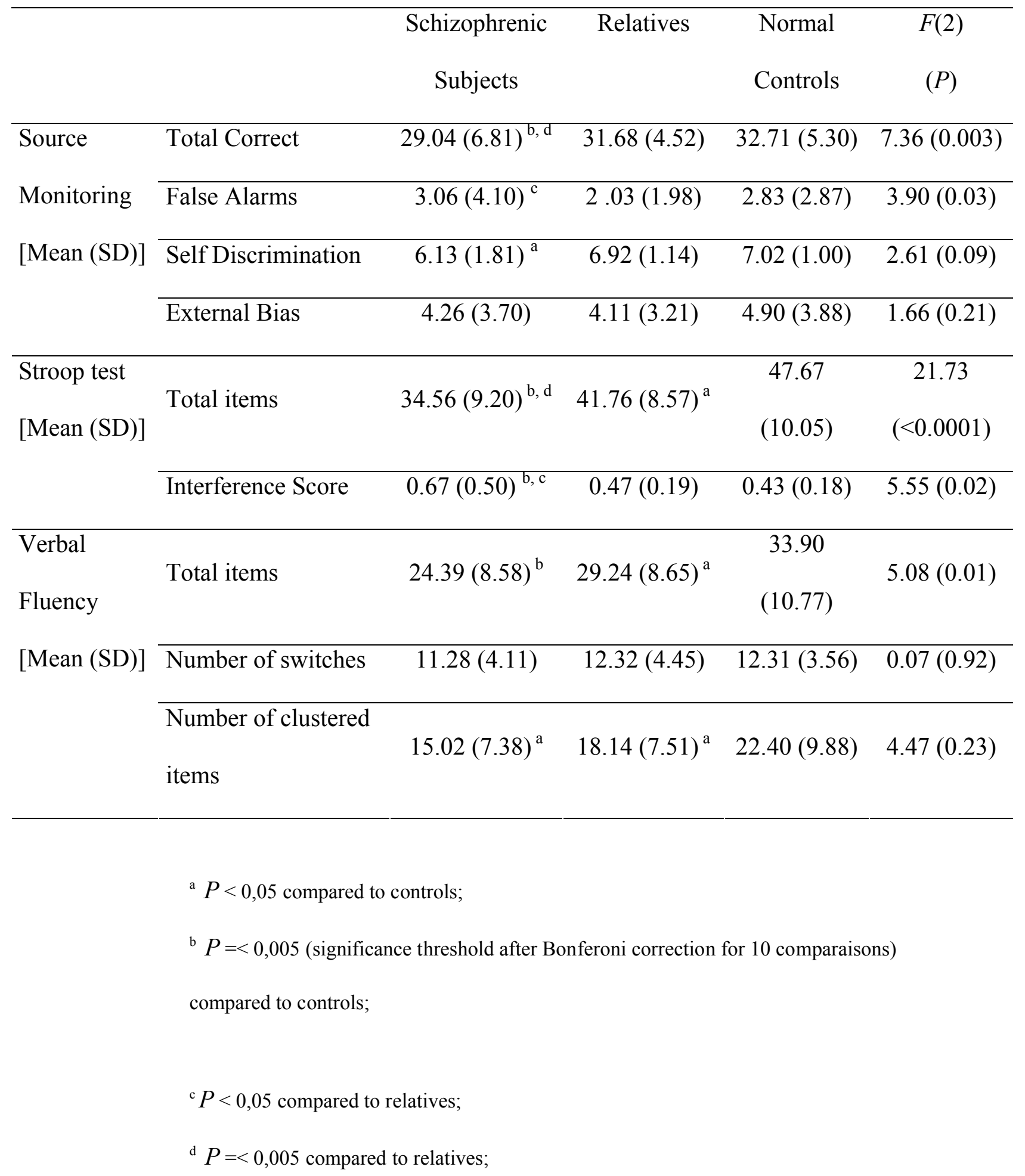


Table 4 Significant partial correlations [Pearson's $r(P)$ ] between clinical and cognitive variables

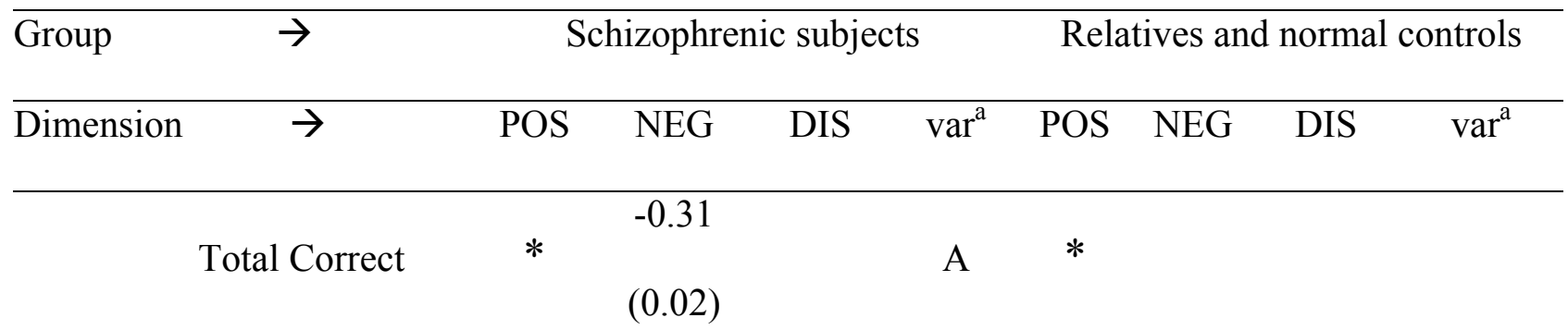

Source

False Alarms * * *

Monitoring

Self

Discrimination

External Bias

$*$

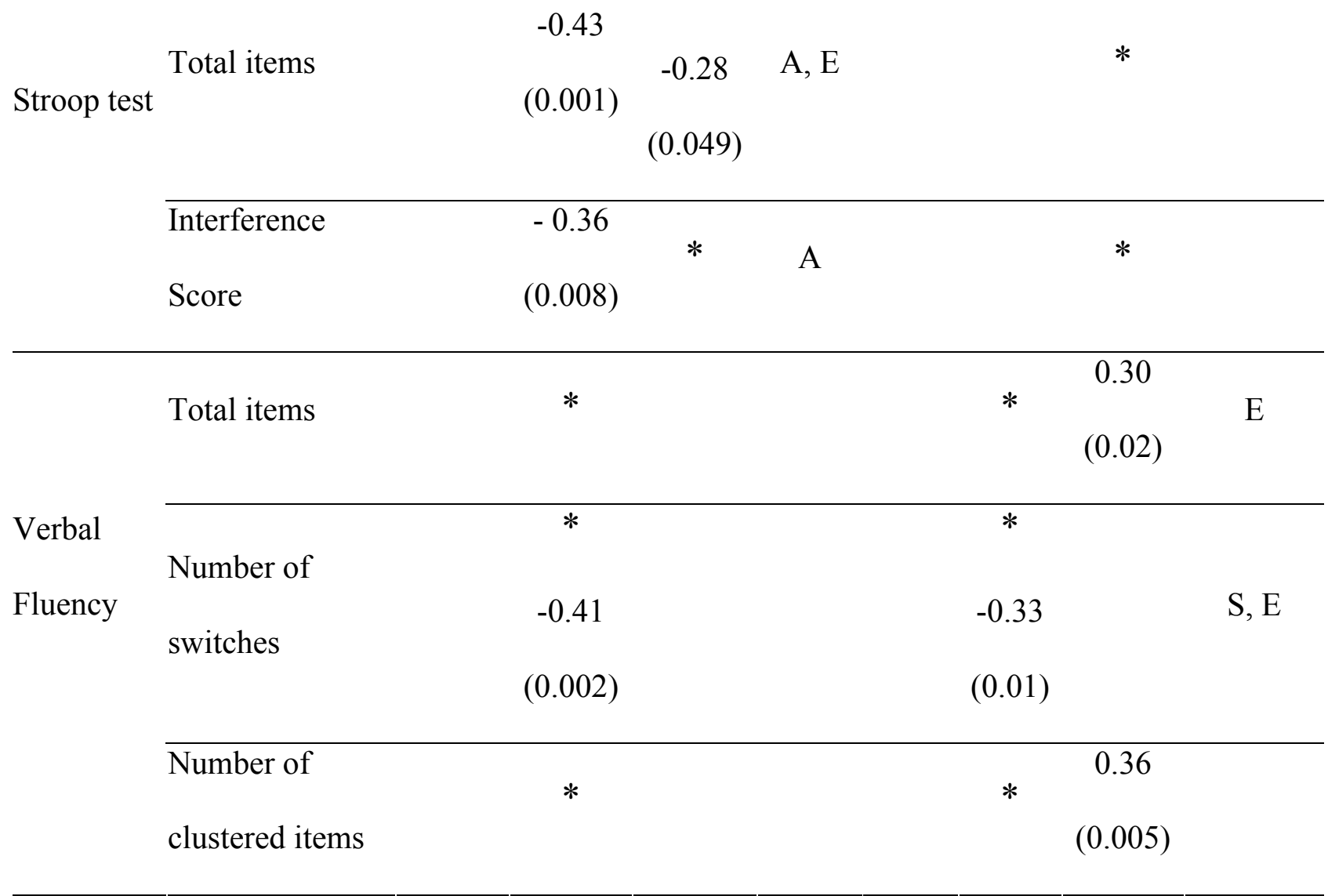


* = expected significant correlations; Negative correlations reflect better cognitive performances in less symptomatic subjects

${ }^{\mathrm{a}}$ Variables held in the final model (at 0.1 threshold) and used in the calculation of partial correlations $(\mathrm{A}=$ age, $\mathrm{S}$ $=$ sex, $\mathrm{E}=$ education $)$ 